\title{
Délactosation du lait par cellules de levures, en phase de reproduction, pour la production de yoghourt
}

\author{
par \\ J. ROSSI et M. TERENCE-JEMMET \\ Institut de Microbiologie Laitière-fromagère \\ Faculté d'Agronomie de Pérouse (Italie)
}

Les travaux concernant la réduction du lactose dans le lait sont liés à certains aspects d'intolérance déterminés par des facteurs encore mal définis. Les recherches effectuées conduisent à poser le problème sur des bases génétiques ou sur des conditions particulières de milieu et d'habitudes alimentaires [1, 2, 3]. D'autres aspects, liés à l'individu, sont déterminants dans la manifestation de cas d'intolérance au lactose : par exemple, l'âge provoque une intensification graduelle de cette anomalie métabolique, bien différente de celle qui se manifeste seulement par une mauvaise assimilation du lactose $[4,5,6,7,8]$. On a mis également en évidence un rapport entre la diminution des enzymes concernant la lactase et l'administration de médicaments [9], en particulier de certains antibiotiques [10]. L'intolérance est fréquemment associée aussi à d'autres disfonctionnements tels que les syndromes cœliaques ou l'assimilation défectueuse du calcium.

Les procédés qui permettent la délactosation du lait sont basés essentiellement sur l'emploi de moyens physiques et biologico-biochimiques. L'ultrafiltration et l'osmose inverse [11, 12, 13], parmi les premiers, ont été utilisées indirectement pour la délactosation dans la mesure où elles ont pour but essentiel de concentrer surtout la fraction protéique du lait $[14,15,16,17,18]$, du sérum [19] et du petit-lait.

Le procédé biochimique peut être réalisé en employant directement des lactases de différentes provenances : eumicétique (levures) et bactérienne, avec de meilleurs résultats dans le premier cas [20]. L'enzyme peut être utilisée à l'état libre $[21,22,23,24,25]$, mais la technologie la plus récente prévoit son immobilisation avec la possi- 
bilité de donner à l'enzyme elle-même une plus longue durée de vie effective et quelquefois aussi une stabilité thermique plus élevée $[26,27,28,29]$. Les systèmes d'immobilisation enzymatique se fondent sur des procédés physiques et chimiques : simple englobement dans un substrat poreux, ou absorption par des supports insolubles, certaines fonctions de l'enzyme étant liées aux supports insolubles ou à d'autres substrats comme les dérivés triaziniques de la cellulose, les monomères acryliques et le triacétate de cellulose. Ce type de procédé permet certainement de donner une solution à un certain nombre de manifestations : en réalité, le lactose en tant que tel subit des réductions qui sont surtout fonction de la quantité d'enzymes immobilisées, de la température et du temps de l'hydrolyse. Cependant, d'autres inconvénients subsistent que l'on peut attribuer aux dérivés de cette même hydrolyse, et particulièrement à la galactone, plusieurs fois considérée comme responsable de certaines altérations [30].

La délactosation du lait peut aussi être réalisée par l'emploi direct de micro-organismes galactosidasiques co-actifs. C'est ainsi qu'en se limitant à la production du lait alimentaire, on a utilisé particulièrement certaines levures. Cette méthode est présentée avec l'utilisation de cellules de levure en phase de reproduction [31] et en employant Saccharomyces fragilis et Saccharomyces lactis [32] dans des conditions et des temps de délactosation technologiquement valables.

Nos travaux s'inscrivent dans le sujet en question en ce qu'ils examinent la possibilité de délactoser le lait avec des cellules de levure en phase de multiplication et tentent de déterminer les conditions nécessaires pour parvenir à un procédé technologiquement valable soit pour la seule production de lait délactosé, soit en vue de l'utilisation de ce lait dans la fabrication du yoghourt.

\section{METHODOLOGIE}

Les recherches ont été articulées en phases successives afin d'arriver à l'individualisation des conditions optimales définies en termes de p. 100 de l'hydrolyse du lactose et des temps techniques les plus idoines à la seule délactosation du lait et à son utilisation pour le yoghourt.

\section{Délactosation du lait et production de yoghourt}

A) CONDitions de LA DÉlactosation du LAIT

1) Choix des souches de levures en fonction de la rapidité du processus hydrolytique. 


\section{TABLEAU 1}

Evolution de la délactosation effectuée par souches de levures en phase de reproduction

Kluyveromyces fragilis Jörgensen 1872

Kluyveromyces fragilis Jörgensen 1874

Kluyveromyces fragilis Jörgensen 1875

Kluyveromyces fragilis Jörgensen 1876

Kluyveromyces fragilis Jörgensen 1877

Kluyveromyces fragilis Jörgensen 1878

Torulopsis versatilis (Etchells et Bell) nov. comb. 4181 Torulopsis versatilis (Etchells et Bell) nov. comb. 4182

Torulopsis versatilis (Etchells et Bell) nov. comb. 4183

Torulopsis sphaerica (Hammer et Corbes) Lodder 4495 Torulopsis sphaerica (Hammer et Corbes) Lodder 4496 Torulopsis sphaerica (Hammer et Corbes) Lodder 4497

Torulopsis anomala Lodder et Kreger Van-Rij 4523

Candida pseudotropicalis (Cast.) Basgal 5213

Candida pseudotropicalis (Cast.) Basgal 5214

Candida pseudotropicalis (Cast.) Basgal 5215

Candida pseudotropicalis (Cast.) Basgal 5219

Candida pseudotropicalis (Cast.) Basgal 5223

Brettanomyces anomalus Custers 5925

Brettanomyces anomalus Custers 5926

Brettanomyces anomalus Custers 5927

\begin{tabular}{|c|c|c|}
\hline $\begin{array}{l}\text { Lactose } \\
\text { non hydrolysé } \\
\text { p. } 100\end{array}$ & $\begin{array}{l}\text { Valeur } \\
\text { cellulaire }\end{array}$ & $\mathrm{pH}$ \\
\hline $\begin{array}{l}2.87 \\
2.87 \\
3.50 \\
3.16 \\
3.01 \\
2.98\end{array}$ & $\begin{array}{r}68 \\
92 \\
71 \\
126 \\
72 \\
196\end{array}$ & $\begin{array}{l}5.98 \\
6.03 \\
6.20 \\
6.04 \\
6.02 \\
6.00\end{array}$ \\
\hline $\begin{array}{l}3.81 \\
3.50 \\
3.65\end{array}$ & $\begin{array}{l}88 \\
59 \\
64\end{array}$ & $\begin{array}{l}6.70 \\
7.08 \\
6.80\end{array}$ \\
\hline $\begin{array}{l}2.43 \\
2.39 \\
2.76\end{array}$ & $\begin{array}{l}480 \\
409 \\
352\end{array}$ & $\begin{array}{l}5.80 \\
5.72 \\
5.74\end{array}$ \\
\hline 3.70 & 46 & 6.35 \\
\hline $\begin{array}{l}2.58 \\
2.65 \\
2.28 \\
3.61 \\
2.43\end{array}$ & $\begin{array}{l}347 \\
492 \\
322 \\
196 \\
387\end{array}$ & $\begin{array}{l}5.67 \\
5.67 \\
5.66 \\
6.88 \\
5.72\end{array}$ \\
\hline $\begin{array}{l}3.58 \\
3.23 \\
3.61\end{array}$ & $\begin{array}{l}38 \\
25 \\
28\end{array}$ & $\begin{array}{l}6.38 \\
6.38 \\
6.37\end{array}$ \\
\hline 4.60 & & \\
\hline
\end{tabular}

Lait entier

La valeur cellulaire est le résultat de la numération moyenne effectuée selon Breed. 
Ce choix a été effectué sur vingt et une souches de levures des genres Saccharomyces, Torulopsis, Candida, Brettanomyces, prélevées sur plaques de Malt-agar ( $24 \mathrm{~h})$ et qui ont été ensemencées dans du lait stérile (15 p. 100 environ), en concentration cellulaire de $260 \times 4 \times$ $10^{\circ} / \mathrm{ml}$. Après $8 \mathrm{~h}$ d'incubation $\left(37^{\circ} \mathrm{C}\right.$ pour Kluyveromyces fragilis et $30^{\circ} \mathrm{C}$ dans les autres cas) avec agitation (120-130 tours à la minute), la sélection a été effectuée sur la base de l'expression hydrolitique de lactose la plus élevée, associée à la plus faible action acidifiante (tab. 1).

2) Examen de l'influence de la concentration cellulaire et de quelques conditions de développement de Kluyveromyces fragilis 1874 .

Le matériel cellulaire prélevé de la plaque Malt-agar (24 h) a été ensemencé (1 p. 100) dans du lait stérile avec des concentrations égales à $100 \times 4 \times 10^{\circ}$ et $16 \times 4 \times 10^{6} / \mathrm{ml}$, mises respectivement en conditions d'agitation et en condition statique. On a relevé les résultats après $4 \mathrm{~h}, 6 \mathrm{~h}, 8 \mathrm{~h}, 24 \mathrm{~h}$ d'incubation à $37^{\circ} \mathrm{C}$ en fonction du $\mathrm{pH}$, du résidu de lactose et des expressions cellulaires (tab. 2 a). Dans une seconde analyse, l'aspect précédent a été confirmé avec des concentrations cellulaires égales à $273 \times 4 \times 10^{6} / \mathrm{ml}$, en ensemençant le lait stérile dans la proportion de 2 p. 100 (tab. 2 b).

3) Délactosation du lait par des cellules de Kluyveromyces fragilis 1874, prélevées directement sur plaque de Malt-agar et sur des précultures en lait.

On a considéré à cet effet les types suivants de préparation :

a) obtenues avec des cellules directement prélevées sur plaque de Malt-agar ( $24 \mathrm{~h})$, ensemencées en lait stérile dans la concentration de $180 \times 4 \times 10^{6} / \mathrm{ml}$, dans la proportion de $1,5 \mathrm{p} .100$ et mis en incubation à la température de $37^{\circ} \mathrm{C}$ en conditions d'agitation ;

b) obtenues en partant de 20 p. 100 du matériel prélevé sur l'échantillon a) qui a subi déjà $3 \mathrm{~h}$ d'incubation ; ce nouvel échantillon b) est ensuite soumis à une incubation dans la même condition pour $12 \mathrm{~h}$;

c) obtenues avec incubation en conditions à $37^{\circ} \mathrm{C}$ pendant $10 \mathrm{~h}$ après avoir été ensemencé avec un matériel cellulaire (20 p. 100) prélevé sur l'échantillon b) qui a subi 10 h 30 d'incubation.

Les résultats relevés en fonction $\mathrm{du} \mathrm{pH}$, du pourcentage du résidu de lactose et de la numération cellulaire sont indiqués dans le tableau 3.

4) Analyse comparative pour Kluyveromyces fragilis 1874, Candida pseudotropicalis 5215 et Torulopsis sphaerica 4496 sur la base de la provenance du matériel cellulaire.

Pour les trois souches de levures considérées, on a comparé d'abord des conditions différentes d'ensemencement en lait stérile ; cellules prélevées soit directement de plaque de Malt-agar (24 h (M) 


\section{TABLEAU $2 a$}

Métabolisation du lactose en présence de différentes concentrations cellulaires de Kluyveromyces fragilis 1874 à $37^{\circ} \mathrm{C}$

\begin{tabular}{|c|c|c|c|c|c|c|c|c|c|c|c|c|c|}
\hline \multirow{2}{*}{$\begin{array}{l}\text { Concentrations } \\
\text { cellulaires }\end{array}$} & \multirow{2}{*}{$\begin{array}{c}\text { Conditions } \\
\text { d'incubation }\end{array}$} & \multicolumn{4}{|c|}{ Lactose p. 100 non hydrolysé } & \multicolumn{4}{|c|}{$\mathrm{pH}$} & \multicolumn{4}{|c|}{ Valeur cellulaire } \\
\hline & & $4 \mathrm{~h}$ & $6 \mathrm{~h}$ & $8 \mathrm{~h}$ & $24 \mathrm{~h}$ & $4 \mathrm{~h}$ & $6 \mathrm{~h}$ & $8 \mathrm{~h}$ & $24 \mathrm{~h}$ & $4 \mathrm{~h}$ & $6 \mathrm{~h}$ & $8 \mathrm{~h}$ & $24 \mathrm{~h}$ \\
\hline $99 \times 4 \times 10^{8} / \mathrm{ml}$ & A & 4.37 & 3.36 & 1.43 & 0 & 5.98 & 5.78 & 5.72 & 5.30 & 251 & 350 & 380 & 390 \\
\hline $99 \times 4 \times 10^{3} / \mathrm{ml}$ & $\mathrm{S}$ & 4.41 & 4.23 & 3.92 & 1.99 & 6.06 & 5.86 & 5.81 & 5.60 & 15 & 19 & 37 & 84 \\
\hline $16 \times 4 \times 10^{6} / \mathrm{ml}$ & A & 4.49 & 4.34 & 3.27 & 0.07 & 6.36 & 6.02 & 5.77 & 5.30 & 14 & 54 & 187 & 227 \\
\hline $16 \times 4 \times 10^{6} / \mathrm{ml}$ & $\mathrm{S}$ & 4.57 & 4.61 & 4.46 & 2.36 & 6.30 & 6.15 & 5.99 & 5.60 & 4 & 12 & 25 & 40 \\
\hline Lait entier & & \multicolumn{4}{|c|}{4.61} & \multicolumn{4}{|c|}{6.55} & & & & \\
\hline
\end{tabular}

$\mathrm{A}=$ Conditions d'agitation.

$\mathrm{S}=$ Conditions d'immersion.

La valeur cellulaire est le résultat de la numération moyenne effectuée selon Breed. 


\section{TABLEAU $2 b$}

Métabolisation du lactose en présence de concentrations cellulaires élevées de Kluyveromyces fragilis 1874 à $37^{\circ} \mathrm{C}$ et en condition aérée d'incubation

\begin{tabular}{|c|c|c|c|c|c|c|c|c|c|c|c|c|}
\hline \multirow{2}{*}{$\begin{array}{l}\text { Concentration } \\
\text { cellulaire }\end{array}$} & \multicolumn{4}{|c|}{ Lactose p. 100 non hydrolysé } & \multicolumn{4}{|c|}{$\mathrm{pH}$} & \multicolumn{4}{|c|}{ Valeur cellulaire } \\
\hline & $4 \mathrm{~h}$ & $6 \mathrm{~h}$ & $8 \mathrm{~h}$ & $24 \mathrm{~h}$ & $4 \mathrm{~h}$ & $6 \mathrm{~h}$ & $8 \mathrm{~h}$ & $24 \mathrm{~h}$ & $4 \mathrm{~h}$ & $6 \mathrm{~h}$ & $8 \mathrm{~h}$ & $24 \mathrm{~h}$ \\
\hline $273 \times 4 \times 10^{6} / \mathrm{ml}$ & 3.74 & 2.62 & 1.17 & 0 & 5.98 & 5.76 & 5.65 & nd & 2288 & 320 & 377 & nd \\
\hline Lait entier & \multicolumn{4}{|c|}{4.84} & \multicolumn{4}{|c|}{6.50} & & & & \\
\hline
\end{tabular}

nd $=$ non déterminé.

La valeur cellulaire est le résultat de la numération moyenne effectuée selon Breed. 


\section{TABLEAU 3}

Métabolisation du lactose en présence des cellules de Kluyveromyces fragilis 1874 prélevées directement de la plaque de Malt-agar (1) et de préculture en lait (2-3). Conditions aérées d'incubation à la température de $37^{\circ} \mathrm{C}$

\begin{tabular}{|c|c|c|c|c|c|c|c|c|c|c|}
\hline \multirow{2}{*}{ Essai $n^{\circ}$} & \multicolumn{5}{|c|}{ Lactose p. 100 non hydrolysé } & \multicolumn{5}{|c|}{$\mathrm{pH}$} \\
\hline & $\mathrm{Oh}$ & $8 \mathrm{~h}$ & $10 \mathrm{~h}$ & $12 \mathrm{~h}$ & $14 \mathrm{~h}$ & $0 \mathrm{~h}$ & $8 \mathrm{~h}$ & $10 \mathrm{~h}$ & $12 \mathrm{~h}$ & $14 \mathrm{~h}$ \\
\hline $1=\mathrm{a}$ & 3.99 & nd & 2.25 & 1.14 & 0.15 & 6.50 & nd & 5.72 & 5.60 & 5.55 \\
\hline $2=b$ & 3.99 & nd & 0.77 & 0.00 & 0.00 & 6.44 & nd & 5.66 & 5.55 & nd \\
\hline $3=c$ & 3.39 & 0.11 & 0,00 & 0.00 & 0.00 & 6.19 & 5.62 & 5.54 & nd & nd \\
\hline
\end{tabular}

nd $=$ non déterminé.

1 = Matériel cellulaire prélevé directement de la plaque Malt-agar.

2 = Matériel cellulaire ( 20 p. 100) prélevé de l'échantillon 1 après 3 h. d'incubation.

3 = Matériel cellulaire ( $20 \mathrm{p} .100)$ prélevé de 1'échantillon 2 après $10 \mathrm{~h} 30$ d'incubation. 
$\left(275 \times 4 \times 10^{6} / \mathrm{ml}\right)$ dans la proportion de $1 \mathrm{p}$. 100 , soit une préculture (P) utilisée dans la proportion de 5 p. 100, après $6 \mathrm{~h}$ d'incubation. Les préparations ainsi obtenues ont été mises en incubation à $37^{\circ} \mathrm{C}$ en conditions d'agitation et les résultats sont reportés dans le tableau $4 \mathrm{a}$. On a répété l'analyse (tab. 4 b) en faisant varier seulement la température d'incubation $\left(30^{\circ} \mathrm{C}\right.$ pour Candida pseudotropicalis 5215 et Torulopsis sphaerica 4496).

\section{B) Délactosation du laIt POUR LA PRODUCTION DU YOgHOURT}

On a obtenu une première préculture en utilisant seulement Kluyveromyces fragilis 1874 et Candida pseudotropicalis 5215 à partir de plaque de Malt-agar $(24 \mathrm{~h})$ avec ensemencement de 1 p. 100 en lait stérile d'une concentration cellulaire respectivement de 265 et $350 \times 4 \times 10^{6} / \mathrm{ml}$ (tab. $5 \mathrm{a}$ ). On a obtenu une seconde préculture, définie aussi culture de travail, à partir de la précédente, à la $12^{\mathrm{e}} \mathrm{h}$ d'incubation avec l'ensemencement en lait stérile dans la proportion de 10 p. 100 (tab. 5 b). Toutes les précultures ont été mises en incubation à la température de $37^{\circ} \mathrm{C}$ en conditions d'agitation.

On a effectué la délactosation du lait dans des ballons à trois ouvertures d'un volume de 41 ; dans l'un on avait introduit un dispositif à hélice pour l'agitation mécanique (140-160 tours à la minute). Le lait à délactoser a été ensemencé avec 10 p. 100 de la seconde préculture de Kluyveromyces fragilis 1874 et de Candida pseudotropicalis 5215 après $12 \mathrm{~h}$ d'incubation. On a effectué la délactosation dans les deux cas (tab. $6 \mathrm{a}$ et $6 \mathrm{~b}$ ) avec un contrôle périodique du $\mathrm{pH}$, du résidu de lactose et des levures par le système de dilution en série décimale.

\section{C) Production Du Yoghourt AVEC DU LAIT DÉlactosé}

On a ajouté du lait entier stérile ( $\mathrm{pH} 6,2$; lactose 4,26 p. 100) au lait délactosé pour élever la proportion de lactose à 1,5 p. 100 et le $\mathrm{pH}$ à des valeurs supérieures à 5,75 . Selon nos expériences préliminaires, ces conditions sont indispensables pour garantir un processus régulier du métabolisme des ferments lactiques afin d'obtenir un caillé consistant et sans défaut et d'empêcher les processus de coagulation du lait délactosé pendant la pasteurisation.

Le lait ainsi intégré au lait entier a été soumis à la pasteurisation dans les mêmes récipients à la température de $80^{\circ} \mathrm{C}$ pendant $10 \mathrm{mn}$ et maintenu en agitation. Après l'avoir refroidi à $42^{\circ} \mathrm{C}$, on l'a ensemencé avec 1 p. 100 d'une souche en APTG de Lactobacillus bulgaricus $\mathrm{L}_{2}$ et de Streptococcus thermophilus $\mathrm{S}_{4}$, respectivement, en concentration cellulaire de 180 et $100 \times 4 \times 10^{8} / \mathrm{ml}$. On l'a ensuite réparti dans des récipients à yoghourt et mis en incubation à la température de $40^{\circ} \mathrm{C}-41^{\circ} \mathrm{C}$ pendant $5 \mathrm{~h}$ puis conservé à $4^{\circ} \mathrm{C}-5^{\circ} \mathrm{C}$.

Parallèlement, on a effectué une expérience avec du lait non délactosé, traité selon les mêmes modalités. Sur tous les échantillons 
TABLEAU 4 a

Analyse comparative pour Kluyveromyces fragilis 1874 - Candida pseudotropicalis 5215 - Torulopsis sphaerica 4496 sur la base de la provenance du matériel cellulaire : de la plaque Malt-agar $(M)$ et de préculture de $6 \mathrm{~h}(\mathrm{P})$ ensemencé en concentration de $5 \mathrm{p}$. 100 . Incubation à $37^{\circ} \mathrm{C}$ en condition d'agitation

\begin{tabular}{|c|c|c|c|c|c|c|c|c|c|}
\hline \multirow{2}{*}{ Souches microbiennes } & \multirow{2}{*}{$\begin{array}{l}\text { Origine du } \\
\text { matériel } \\
\text { cellulaire }\end{array}$} & \multicolumn{4}{|c|}{ Lactose p. 100 non hydrolysé } & \multicolumn{4}{|c|}{$\mathrm{pH}$} \\
\hline & & $8 \mathrm{~h}$ & $10 \mathrm{~h}$ & $12 \mathrm{~h}$ & $14 \mathrm{~h}$ & $8 \mathrm{~h}$ & $10 \mathrm{~h}$ & $12 \mathrm{~h}$ & $14 \mathrm{~h}$ \\
\hline Kluyveromyces fragilis & M & 1.13 & 0.0 & 0.0 & 0.0 & 5.45 & 5.45 & 5.45 & 5.40 \\
\hline Kluyveromyces fragilis & $\mathrm{P}$ & 0.74 & 0.43 & 0.00 & 0.00 & 5.55 & 5.50 & 5.50 & 5.45 \\
\hline Torulopsis sphaerica & M & 4.15 & 4.41 & 4.41 & 4.61 & 6.24 & 6.18 & 6.14 & 6.14 \\
\hline Torulopsis sphaerica & $P$ & 4.19 & 4.26 & 4.30 & 4.34 & 6.24 & 6.22 & 6.20 & 6.20 \\
\hline Candida pseudotropicalis & M & 0.77 & 0.0 & 0.0 & 0.0 & 5.55 & 5.55 & 5.50 & 5.50 \\
\hline Candida pseudotropicalis & $P$ & 1.39 & 0.58 & 0.07 & 0.0 & 5.53 & 5.50 & 5.50 & 5.50 \\
\hline Lait entier & & \multicolumn{4}{|c|}{4.08} & \multicolumn{4}{|c|}{6.30} \\
\hline
\end{tabular}


Analyse comparative pour Kluyveromyces fragilis 1874 - Candida pseudotropicalis 5215 - Torulopsis sphaerica 4496 sur la base de la provenance du matériel cellulaire : de plaque de Malt-agar $(\mathrm{M})$ et de préculture de $6 \mathrm{~h}(\mathrm{P})$ ensemencé en concentration de $5 \mathrm{p}$. 100 . Incubation en condition d'agitation à $37^{\circ} \mathrm{C}$ pour Kluyveromyces fragilis, à $30^{\circ} \mathrm{C}$ pour Torulopsis sphaerica et Candida pseudotropicalis

\begin{tabular}{|c|c|c|c|c|c|c|}
\hline \multirow{2}{*}{ Souches microbiennes } & \multirow{2}{*}{$\begin{array}{l}\text { Température } \\
\text { d'incubation }\end{array}$} & \multirow{2}{*}{$\begin{array}{l}\text { Origine du matériel } \\
\text { cellulaire }\end{array}$} & \multicolumn{4}{|c|}{ Lactose p. 100 non hydrolysé } \\
\hline & & & $8 \mathrm{~h}$ & $10 \mathrm{~h}$ & $12 \mathrm{~h}$ & $14 \mathrm{~h}$ \\
\hline Kluyveromyces fragilis & $37^{\circ} \mathrm{C}$ & M & 1.43 & nd & 0.0 & 0.0 \\
\hline Kluyveromyces fragilis & $37^{\circ} \mathrm{C}$ & $P$ & 0.95 & 0.43 & 0.0 & 0.0 \\
\hline Torulopsis sphaerica & $30^{\circ} \mathrm{C}$ & M & 2.06 & 1.25 & 0.58 & 0.0 \\
\hline Torulopsis sphaerica & $30^{\circ} \mathrm{C}$ & $\mathrm{P}$ & 1.95 & 1.80 & 1.32 & 0.36 \\
\hline Candida pseudotropicalis & $30^{\circ} \mathrm{C}$ & M & 3.23 & 2.76 & 1.99 & 1.10 \\
\hline Candida pseudotropicalis & $30^{\circ} \mathrm{C}$ & $\mathrm{P}$ & 3.39 & 3.20 & 3.05 & 2.17 \\
\hline Lait entier & & & \multicolumn{4}{|c|}{4.37} \\
\hline
\end{tabular}


Kluyveromyces fragilis 1874 et Candida pseudotropicalis 5215 en phase de préculture en lait. Incubation en condition d'agitation à $37^{\circ} \mathrm{C}$. Cellules prélevées de plaque de Malt-agar

\begin{tabular}{|c|c|c|c|}
\hline Souches microbiennes & $\begin{array}{l}\text { Lactose p. } 100 \text { non hydrolysé } \\
\qquad 12 \mathrm{~h}\end{array}$ & $\begin{array}{l}\mathrm{pH} \\
12 \mathrm{~h}\end{array}$ & $\begin{array}{l}\text { Valeur cellulaire } \\
\qquad 12 \mathrm{~h}\end{array}$ \\
\hline Kluyveromyces fragilis & 0.0 & 5.55 & $107 \times 4 \times 10^{6} / \mathrm{ml}$ \\
\hline Candida pseudotropicalis & 0.0 & 5.62 & $101 \times 4 \times 10^{6} / \mathrm{ml}$ \\
\hline
\end{tabular}

La valeur cellulaire est le résultat de la numération moyenne effectuée selon Thomas Zeiss.

\section{TABLEAU $5 b$}

Kluyveromyces fragilis 1874 et Candida pseudotropicalis 5215 en phase de culture de travail après incubation en condition d'agitation à $37^{\circ} \mathrm{C}$.

Cellules prélevées de la préculture en lait (tab. $5 \mathrm{a}$ ) en proportion de $10 \mathrm{p} .100$

\begin{tabular}{|c|c|c|c|c|c|c|}
\hline \multirow{2}{*}{ Souches microbiennes } & \multicolumn{2}{|c|}{ Lactose p. 100 non hydrolysé } & \multicolumn{2}{|c|}{$\mathrm{pH}$} & \multicolumn{2}{|c|}{ Valeur cellulaire/ml } \\
\hline & $0 \mathrm{~h}$ & $12 \mathrm{~h}$ & $0 \mathrm{~h}$ & $12 \mathrm{~h}$ & $0 \mathrm{~h}$ & $12 \mathrm{~h}$ \\
\hline Kluyveromyces fragilis & 3.70 & 0.0 & 5.87 & 5.45 & $18 \times 10^{6}$ & $45 \times 10^{6}$ \\
\hline Candida pseudotropicalis & 4.08 & 0.0 & 6.06 & 5.42 & $12 \times 10^{6}$ & $20 \times 10^{7}$ \\
\hline
\end{tabular}

La numération cellulaire a été relevée sur WL medium Difco.

Lait entier avant l'addition de la préculture : - pour $K$. fragilis :

lactose p. $100=4,07$

mat. grasse p. $100=1,25$

- pour C. pseudotropicalis : lactose p. $100=4,48$

mat. grasse p. $100=1,25$ 


\section{TABLEAU 6 a}

Délactosation du lait par Kluyveromyces fragilis 1874 et Candida pseudotropicalis 5215 employés en phase de "culture du travail » $\left(10\right.$ p. 100) (tab. 5 a). Conditions aérées d'incubation à $37^{\circ} \mathrm{C}$

Délactosation par

\begin{tabular}{|c|c|c|c|c|c|c|c|}
\hline \multicolumn{4}{|c|}{ Kluyveromyces fragilis 1874} & \multicolumn{4}{|c|}{ Candida pseudotropicalis 5215} \\
\hline $\begin{array}{l}\text { Temps } \\
\text { en } \mathbf{h}\end{array}$ & $\begin{array}{l}\text { Lactose p. } 100 \\
\text { non hydrolysé }\end{array}$ & $\mathrm{pH}$ & $\begin{array}{c}\text { Valeur } \\
\text { cellulaire/ml }\end{array}$ & $\begin{array}{l}\text { Temps } \\
\text { en } \mathrm{h}\end{array}$ & $\begin{array}{l}\text { Lactose p } 100 \\
\text { non hydrolysé }\end{array}$ & $\mathrm{pH}$ & $\begin{array}{c}\text { Valeur } \\
\text { cellulaire } / \mathrm{ml}\end{array}$ \\
\hline 0 & 3.70 & 6.07 & $18 \times 10^{6}$ & 0 & 4.08 & 5.99 & $13 \times 10^{6}$ \\
\hline 2 & 3.20 & 5.83 & $23 \times 10^{6}$ & 2 & 3.47 & 5.79 & $29 \times 10^{8}$ \\
\hline 4 & 2.47 & 5.65 & $36 \times 10^{6}$ & 4 & 3.16 & 5.61 & $41 \times 10^{8}$ \\
\hline 6 & 1.73 & 5.68 & nd & 6 & 2.25 & 5.48 & $41 \times 10^{6}$ \\
\hline 8 & 0.77 & 5.55 & $48 \times 10^{8}$ & 8 & 1.06 & 5.38 & nd \\
\hline \multirow[t]{2}{*}{9.30} & 0.00 & 5.40 & $45 \times 10^{6}$ & 9 & 0.51 & 5.28 & $47 \times 10^{6}$ \\
\hline & & & & 10.30 & 0.00 & 5.24 & $59 \times 10^{8}$ \\
\hline
\end{tabular}

nd $=$ non déterminé.

La numération cellulaire a été relevée sur WL medium Difco.

\begin{tabular}{|c|c|c|}
\hline Lait entier avant l'addition de la préculture : & - pour $K$. fragilis : & $\begin{array}{l}{ }^{\circ} \mathrm{SH} \text { p. } 100 \\
\text { lactose p. } 100 \\
\text { mat. grasse p. } 100\end{array}$ \\
\hline & - pour C. pseudotropicalis : & $\begin{array}{l}{ }^{\circ} \mathrm{SH} \text { p. } 100 \\
\text { lactose p. } 100 \\
\text { mat. grasse p. } 100\end{array}$ \\
\hline
\end{tabular}




\section{TABLEAU $6 b$}

Délactosation du lait par Kluyveromyces fragilis 1874 et Candida pseudotropicalis 5215 employés en phase de "culture du travail » $\left(10\right.$ p. 100) (tab. 5 b). Conditions aérées d'incubation à $37^{\circ} \mathrm{C}$

\section{Délactosation par}

\section{Kluyveromyces fragilis 1874}

\begin{tabular}{|c|c|c|c|c|c|c|c|}
\hline $\begin{array}{l}\text { Temps } \\
\text { en } \mathrm{h}\end{array}$ & $\begin{array}{l}\text { Lactose p. } 100 \\
\text { non hydrolysé }\end{array}$ & $\mathrm{pH}$ & $\begin{array}{l}\text { Valeur } \\
\text { cellulaire }\end{array}$ & $\begin{array}{c}\text { Temps } \\
\text { en } \mathrm{h}\end{array}$ & $\begin{array}{l}\text { Lactose p. } 100 \\
\text { non hydrolysé }\end{array}$ & $\mathrm{pH}$ & $\begin{array}{l}\text { Valeur } \\
\text { cellulaire }\end{array}$ \\
\hline 0 & 3.58 & 6.25 & $11 \times 10^{6}$ & 0 & 3.60 & 6.28 & $12 \times 10^{6}$ \\
\hline 2 & 3.50 & 5.80 & $11 \times 10^{6}$ & 2 & 3.50 & 5.86 & $15 \times 10^{6}$ \\
\hline 4 & 2.69 & 5.69 & $35 \times 10^{6}$ & 4 & 2.84 & 5.70 & $50 \times 10^{6}$ \\
\hline 6 & 1.73 & 5.65 & $99 \times 10^{6}$ & 6 & 1.73 & 5.60 & $80 \times 10^{6}$ \\
\hline 8 & 0.54 & 5.58 & $110 \times 10^{6}$ & 8 & 0.51 & 5.58 & $145 \times 10^{6}$ \\
\hline 9 & 0.00 & 5.55 & $145 \times 10^{6}$ & 9 & 0.00 & 5.62 & $192 \times 10^{6}$ \\
\hline
\end{tabular}

La numération cellulaire a été relevée sur WL medium Difco.

Lait entier avant l'addition de la préculture : - pour $K$. fragilis :

$$
\text { - pour C. pseudotropicalis : }
$$

${ }^{\circ} \mathrm{SH}$ p. 100

$=7,50$

lactose p. $100=3,94$

mat. grasse p. $100=1,80$

${ }^{\circ} \mathrm{SH}$ p. $100=7,60$

lactose p. $100=3,96$

mat. grasse p. $100=2,10$ 
de yoghourt on a effectué des analyses après 0 h-18 h pour établir les différences qui peuvent se manifester entre les diverses préparations.

Selon le procédé standard de numération on a défini l'aspect quantitatif des lactobacilles, des streptocoques, éventuellement des levures, l'évolution acidométrique en fonction du $\mathrm{pH}$ et du résidu lactosé (tab. 7).

\section{Analyse du lait entier, du lait délactosé et du yoghourt}

A) Analyse microbiologioue :

- numération des lactobacilles : effectuée par des dilutions en série décimale sur APTO medium [33] en anaérobiose avec incubation à $37^{\circ} \mathrm{C}$ pendant $5 \mathrm{j}$;

- numération des streptocoques lactiques : effectuée par dilutions en série décimale sur APTS medium [33] en présence de 0,1 ml de 2-3-5 triphényltétrazolium chlorure (solution 1,5 p.100), de $1 \mathrm{ml}$ d'acide glutamique (sol. 15 p. 100) en boîtes de Pétri avec une couche de gélose à l'eau ( $2 \mathrm{p} .100$ ), après $5 \mathrm{j}$ d'incubation à $37^{\circ} \mathrm{C}$;

- numération des levures : elle a été effectuée directement au microscope (système Thomas Zeiss, Breed) et sur WL medium Difco selon une série de dilutions décimales avec incubation à $30^{\circ} \mathrm{C}$ pendant $5 \mathrm{j}$.

B) ANalyse Chimique et physico-chimidue

On a mesuré :

- le pH avec un pHmètre Metrohm Herisau E 300B ;

- l'acidité titrable selon le procédé Soxhlet-Henkel ;

- le lactose, comme lactose anhydre selon la méthode officielle d'analyse, après déprotéinisation avec Carrez I et Carrez II [34].

\section{Résultats et discussion}

Dans la série d'opérations considérées, l'examen des conditions expérimentales nécessaires pour déterminer le processus de délactosation du lait permet de retenir les espèces Kluyveromyces fragilis, Candida pseudotropicalis et Torulopsis sphaerica (tab. 1) comme les plus adéquates. En particulier, dans les conditions réalisées, après 8 h d'incubation, Kluyveromyces fragilis 1874 a permis une hydrolyse de 37 p. 100, Torulopsis sphaerica 4496 de 48 p. 100 et Candida pseudotropicalis 5215 de 50 p. 100 . Avec ces mêmes souches, on a réalisé, en outre, la méthode sélective ici proposée dans des conditions optimales, car, à la différence des autres, elles n'entraînent pas un relèvement très remarquable des variations du $\mathrm{pH}$.

Afin de perfectionner le procédé, on a examiné ensuite, en se limitant à Kluyveromyces fragilis 1874, l'influence de certains para- 
$T A B L E A U 7$

Analyse du développement des ferments lactiques da ns le lait délactosé en comparaison avec le lait témoin

\begin{tabular}{|c|c|c|c|c|c|c|c|c|c|c|}
\hline & \multicolumn{8}{|c|}{ Lait délactosé par } & \multirow{2}{*}{\multicolumn{2}{|c|}{$\begin{array}{c}\text { Lait } \\
\text { non délactosé }\end{array}$}} \\
\hline & \multicolumn{2}{|c|}{$\begin{array}{l}\text { Kluyveromyces } \\
\text { fragilis } 1874\end{array}$} & \multicolumn{2}{|c|}{$\begin{array}{l}\text { Kluyveromyces } \\
\text { fragilis } 1874\end{array}$} & \multicolumn{2}{|c|}{$\begin{array}{c}\text { Candida } \\
\text { pseudotropicalis }\end{array}$} & \multicolumn{2}{|c|}{$\begin{array}{c}\text { Candida } \\
\text { pseudotropicalis }\end{array}$} & & \\
\hline & $0 \mathrm{~h}$ & $18 \mathrm{~h}$ & $0 \mathrm{~h}$ & $18 \mathrm{~h}$ & $0 \mathrm{~h}$ & $18 \mathrm{~h}$ & $\mathrm{Oh}$ & $18 \mathrm{~h}$ & $0 \mathrm{~h}$ & $18 \mathrm{~h}$ \\
\hline $\begin{array}{l}\text { Lactose p. } 100 \\
\text { non hydrolysé }\end{array}$ & 1.50 & 0.69 & 1.50 & 0.88 & 1.50 & 0.84 & 1.50 & 0.91 & 4.26 & 3.47 \\
\hline $\mathrm{pH}$ & 5.92 & 4.70 & 5.81 & 4.70 & 5.86 & 4.70 & 5.76 & 4.40 & 6.20 & 4.70 \\
\hline Streptocoques/ml & $34 \times 10^{4}$ & $41 \times 10^{6}$ & $36 \times 10^{4}$ & $28 \times 10^{6}$ & $66 \times 10^{4}$ & $59 \times 10^{6}$ & $67 \times 10^{4}$ & $37 \times 10^{6}$ & $68 \times 10^{4}$ & $13 \times 10^{7}$ \\
\hline Lactobacilles/ml & $16 \times 10^{5}$ & $94 \times 10^{6}$ & $14 \times 10^{5}$ & $19 \times 10^{7}$ & $19 \times 10^{5}$ & $81 \times 10^{6}$ & $19 \times 10^{5}$ & $63 \times 10^{6}$ & $22 \times 10^{5}$ & $21 \times 10^{7}$ \\
\hline \multicolumn{11}{|l|}{ nd = non déterminé. } \\
\hline \multicolumn{5}{|c|}{ Lait entier avant la coagulation par les ferments lactiques : } & \multicolumn{4}{|c|}{$\begin{aligned} & =7,40 \\
& =4,26 \\
100 & =3,00\end{aligned}$} & & \\
\hline
\end{tabular}


mètres qui ont notamment une incidence sur la rapidité du processus de transformation par des agents microbiens, et ici particulièrement sur le processus de délactosation. En premier lieu, on a considéré l'incidence de la concentration cellulaire initiale en confrontant des cultures en immersion et des cultures largement aérées (tab. 2 a et tab. 2 b). Dans ce dernier, jusqu'à un certain niveau de concentration cellulaire, on a pu faire des observations positives. En effet, le processus se manifeste avec une rapidité différente dans les cas considérés (tab. 2 a) et, en fonction de ce paramètre, passe des valeurs d'ensemencement de $16 \times 4 \times 10^{6} / \mathrm{ml}$ à $99 \times 4 \times 10^{6} / \mathrm{ml}$. Il ne semble pas que des valeurs plus élevées (tab. 2 b) aient une incidence correspondante sur le processus de délactosation. Après $8 \mathrm{~h}$ d'incubation, on peut relever pour les trois concentrations en ordre croissant, les cultures étant agitées, une hydrolyse, respectivement, de 29,0 p. 100 69,0 p. $100-75,0$ p. 100 . Ces différences se réduisent sensiblement avec $24 \mathrm{~h}$ d'incubation. Les conditions d'immersion sont certainement moins déterminantes pour la rapidité du processus ; celle-ci dépend donc encore de la concentration cellulaire.

On a également considéré la possibilité de réduire ultérieurement les temps techniques de délactosation en fonction de l'adaptation de

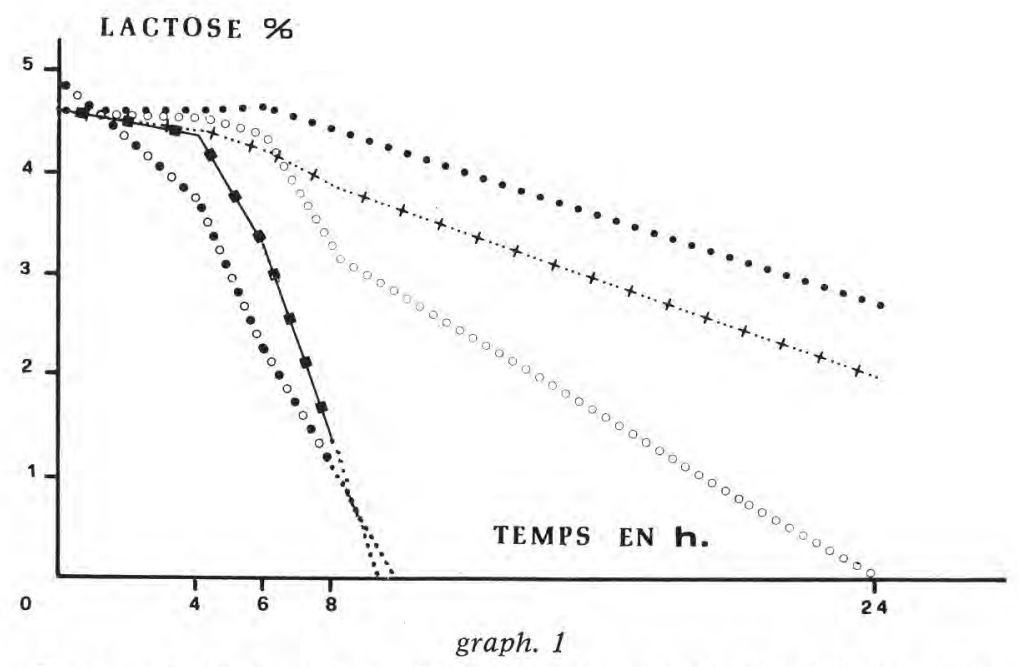

Examen de l'influence de différentes concentrations cellulaires pour Kluyveromyces fragilis 1874 sur la vitesse de métabolisation du lactose à $37^{\circ} \mathrm{C}$ en incubation aérée et statique (tab. $2 \mathrm{a}$ et $2 \mathrm{~b}$ ).
-1- $99 \times 4 \times 10^{6} / \mathrm{ml}$
$+\ldots+\ldots 99 \times 4 \times 10^{6} / \mathrm{ml}$
(A)
$000016 \times 4 \times 10^{6} / \mathrm{ml}$
$\because 16 \times 4 \times 10^{6} / \mathrm{ml}$
- $0273 \times 4 \times 10^{6} / \mathrm{ml}$ 
la souche Kluyveromyces fragilis 1874 au substrat lacté dans la phase de préculture pendant des temps différents ( $3 \mathrm{~h}$ et $10 \mathrm{~h} \mathrm{30}$ ) (tab. 3). Les remarques que l'on peut faire à ce propos conduisent à retenir comme certainement le plus valable l'emploi d'une préculture d'environ $10 \mathrm{~h}$ dans le lait, avec laquelle on peut obtenir une délactosation complète du lait entre $8 \mathrm{~h}$ et $10 \mathrm{~h}$. Ces durées passent à $12 \mathrm{~h}$ si on utilise une préculture de $3 \mathrm{~h}$, et à $14 \mathrm{~h}$ dans le cas d'une culture directement prélevée de la plaque de Malt-agar.

Un autre paramètre a été pris en considération : la température d'incubation qui a été définie optimale à $37^{\circ} \mathrm{C}$ pour Kluyveromyces fragilis 1874 et Candida pseudotropicalis 5215 (tab. 4 a ou 4 b) tandis

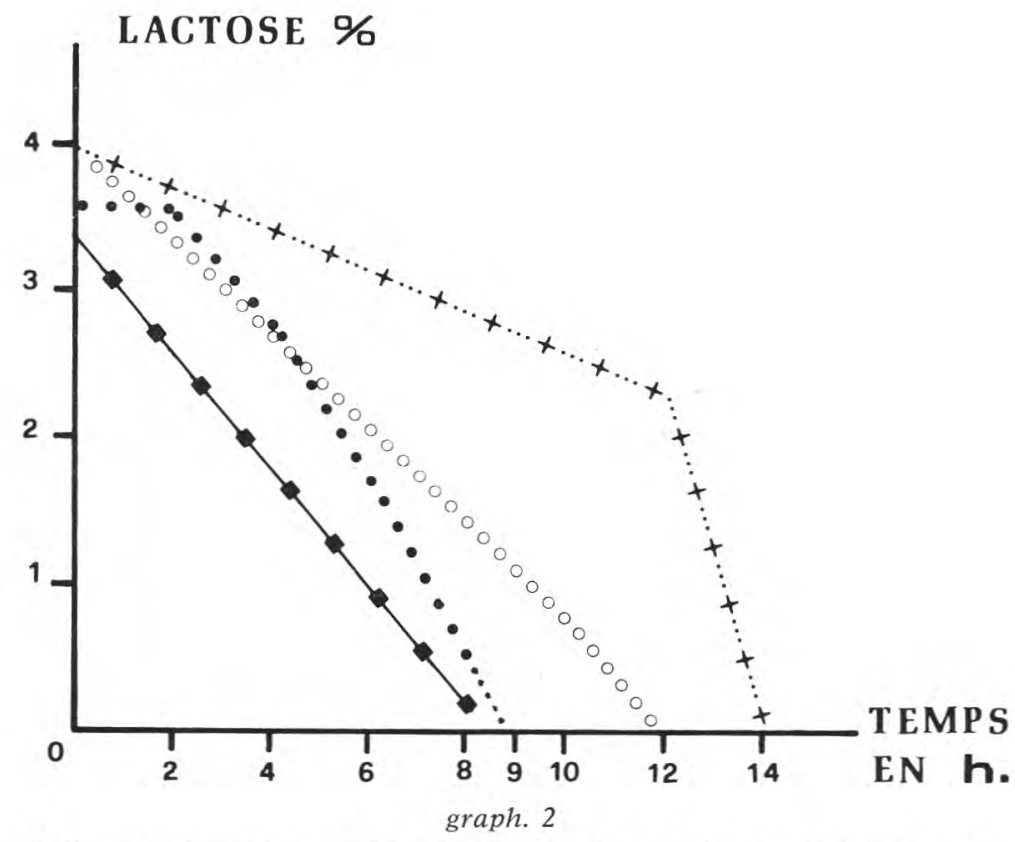

Influence du substrat de provenance du matériel cellulaire pour Kluyveromyces fragilis 1874 sur la vitesse de métabolisation du lactose. Incubation à $37^{\circ} \mathrm{C}$ en aérobiose (tab. 3 et $6 \mathrm{~b}$ ).

$+\ldots+\ldots$ 1) Matériel cellulaire prélevé directement de plaque de Malt-agar.

$\circ \bigcirc \bigcirc \circ$ 2) Matériel cellulaire prélevé de l'échantillon 1, employé en proportion de $20 \mathrm{p}$. 100 après $3 \mathrm{~h}$ d'incubation.

- 3) Matériel cellulaire prélevé après $10 \mathrm{~h} 30$ d'incubation en lait de l'échantillon 2, employé en proportion de 20 p. 100.

4) Matériel cellulaire prélevé après $12 \mathrm{~h}$ d'incubation en lait de la " culture de travail », employé en proportion de 10 p. 100 . 
qu'en se limitant à Torulopsis sphaerica 4496 , elle tombe à $30^{\circ} \mathrm{C}$ (tab. 4 b).

Par conséquent, les conditions optimales de délactosation du lait, selon les paramètres considérés, peuvent être établis selon le schéma d'une métabolisation plus active du lactose par Kluyveromyces fragilis 1874, Candida pseudotropicalis 5215, agissant à la température de $37^{\circ} \mathrm{C}$ avec un matériel d'ensemencement prélevé d'une culture d'environ $10 \mathrm{~h}$ dans le lait, étant donné que la délactosation est fonction de l'adaptation des cellules dans la phase de préculture, de la concentration cellulaire correspondante et quelle est dans tous les cas favorisée par les conditions d'agitation (graph. 1, graph. 2).

Les conditions optimales pour la délactosation du lait, définies dans la phase préliminaire, ont été appliquées pour obtenir un lait à basse teneur de lactose destiné à la production de yoghourt. Les considérations relatives à cette phase de délactosation sont exprimées dans les tableaux 6 a et $6 \mathrm{~b}$ et correspondent à l'emploi d'une proportion d'ensemencement de 10 p. 100 (graph. 2) pour obtenir soit la culture de travail, soit le lait délactosé avec des temps différents dus en partie au pourcentage de lactose du lait ; toutefois, le plus souvent, elle s'effectue en $9 \mathrm{~h}$ environ. On pourrait interrompre la délactosation sans attendre que le processus soit complètement achevé, puisque, dans le cas qui nous occupe, un résidu de lactose de 1,5 p. 100 est nécessaire à la manifestation du métabolisme normal des ferments lactiques (cf. tableau ci-après). Mais l'interruption ne permettrait pas une valeur de $\mathrm{pH}$ qui n'influence pas le processus d'acidification et par conséquent la structure du caillé lui-même (cf. tableau ci-après).

En conséquence, le lait totalement délactosé a été complété par adjonction de lait entier dans la proportion nécessaire pour reporter le pourcentage du lactose à 1,5 p. 100 entraînant en même temps une élévation du $\mathrm{pH}$ (supérieur ou égal à 5,75) nécessaire pour éviter un phénomène de précipitation protéique pendant la phase suivante de pasteurisation qui est indispensable pour l'élimination des levures [35].

L'obtention du yoghourt avec le lait traité dans ces conditions, comparé avec le dérivé du lait non délactosé, n'a pas présenté de différences attribuables à ce procédé de délactosation. Le temps nécessaire pour la coagulation a été, dans tous les cas considérés, de $5 \mathrm{~h}$.

Les observations effectuées sur le yoghourt peuvent être d'ordre technologique et microbiologique.

Dans le premier cas, en ce qui concerne la consistance, on peut faire une remarque en faveur du procédé de délactosation. L'action des levures ne se limiterait pas à la seule phase de délactosation ou 
Lait délactosé par Kluyveromyces fragilis 1874

\begin{tabular}{|c|c|c|c|c|c|c|c|}
\hline $\begin{array}{c}\text { p. } 100 \\
\text { de lactose }\end{array}$ & $\begin{array}{l}\text { coagulation } \\
\text { après h }\end{array}$ & $\begin{array}{c}\text { - SH p. } 100 \text { après } \\
\text { coagulation }\end{array}$ & $\begin{array}{l}\text { pH après } \\
\text { coagulation }\end{array}$ & $\begin{array}{c}\text { p. } 100 \\
\text { de lactose }\end{array}$ & $\begin{array}{l}\text { coagulation } \\
\text { après h }\end{array}$ & $\begin{array}{c}\text { - SH p. } 100 \text { après } \\
\text { coagulation }\end{array}$ & $\begin{array}{l}\text { pH après } \\
\text { coagulation }\end{array}$ \\
\hline 1.00 & 10 & 22.0 & 5.40 & nd & nd & nd & nd \\
\hline 1.40 & 8 & 28.0 & 4.95 & 1.26 & 8 & 22.0 & 5.10 \\
\hline 1.50 & 6 & 28.0 & 4.75 & 1.50 & 6 & 32.0 & 4.65 \\
\hline 2.20 & 6 & 28.0 & 4.75 & 2.20 & 6 & 32.0 & 4.62 \\
\hline
\end{tabular}

\begin{tabular}{|c|c|c|c|}
\hline Lait entier acidifié à valeur de $\mathrm{pH}$ & pH après coagulation & ${ }^{\circ} \mathrm{SH}$ p. 100 après coagulation & Aspect du caillé \\
\hline 5.70 & 4.90 & 26.0 & discret \\
\hline 5.74 & 4.90 & 26.0 & bon \\
\hline 5.80 & 4.85 & 26.0 & très bon \\
\hline 6.60 & 4.75 & 29.0 & très bon \\
\hline
\end{tabular}


à la stabilisation des rapports soit sur la base nutritionnelle, soit en relation avec d'autres facteurs liés au développement microbien ; mais elles influenceraient aussi la consistance du caillé, ainsi que cela a été démontré expérimentalement pour Kloeckera africana [36].

La séparation superficielle du sérum, en quantité très limitée, n'a intéressé que le yoghourt produit avec du lait délactosé et s'est manifestée après un laps de temps assez long.

On doit considérer l'aspect microbiologique en se référant aux deux formes lactiques. En particulier, les streptocoques ont subi un accroissement initial un peu plus élevé dans le cas du lait non délactosé tandis que le comportement des ferments lactiques de forme bactérienne dans la phase d'incubation ne paraît dépendre que dans une faible mesure du processus de délactosation. Il serait intéressant de suivre l'évolution de ces micro-organismes dans le temps pour contrôler l'influence éventuelle des produits du métabolisme des levures dans la phase de délactosation, les cellules ellesmêmes ayant été détruites par la pasteurisation.

\section{R és u m é}

En examinant la possibilité de produire du lait délactosé avec des levures en phase de reproduction, sur un éventail de vingt et une souches (Kluyveromyces, Torulopsis, Candida et Brettanomyces), on a déterminé que les meilleurs résultats étaient obtenus avec Kluyveromyces fragilis 1874 et Candida pseudotropicalis 5215.

Dans les conditions expérimentales réalisées, le processus est conditionné par les paramètres suivants : concentration cellulaire, matériel d'ensemencement (comportement linéairement dépendant jusqu'à $99 \times 4 \times 10^{\circ} / \mathrm{ml}$ ) ; température d'incubation (optimale à $\left.37^{\circ} \mathrm{C}\right)$; conditions d'incubation en culture agitée ; adaptation des cellules du matériel d'ensemencement au substrat lacté dans la phase de préculture.

L'application des conditions optimales pour ces paramètres a permis la délactosation complète en $9 \mathrm{~h}$ environ.

La production du yoghourt obtenu après pasteurisation du lait totalement délactosé, complété avec du lait entier (proportion finale de lactose 1,5 p. 100) n'a pas mis en évidence une différence du temps de coagulation ni de la consistance du yoghourt par comparaison avec le yoghourt obtenu à partir de lait non délactosé.

L'aspect microbiologique du yoghourt est caractérisé par une faible réduction de la flore microbienne dans le cas du yoghourt expérimental par rapport à celle du yoghourt témoin. 


\section{S u m m a r y}

Milk delactosation by RePRoductive yeast CELLS AND HIS RELATIVE UTILIZATION FOR YOGHURT PRODUCTION

In the preliminary delactosation phase a screening among 21 yeast cultures (Kluyveromyces, Torulopsis, Candida and Brettanomyces) is carried out.

Kluyveromyces fragilis 1874 and Candida pseudotropicalis 5215 are resulted the most suitable.

In the experimental conditions, the delactosation process is regulated by the following parameters: cellular concentration (behaviour linearly depending up to $10 \times 4 \times 10^{8} / \mathrm{ml}$ ), temperature and state of incubation (rispectively $37^{\circ} \mathrm{C}$ and stirred conditions), adaptation of the cellular material to medium milk in the preculture stage.

The application of the optimal conditions for delactosation process allows to remove all of the lactose in about $9 \mathrm{~h}$.

The yoghurt production with the wholly delactosed milk, pasteurized after whole milk addition, (lactose final 1,5 p.100) has point out no differences in respect to the whole milk with regard to the clotting time and the firmness.

The microbial aspect of the yoghurt produced by delactosed milk is caracterized by a little decrease of microorganism defined by a logarithmic cycle.

Reçu pour publication en février 1977.

\section{Bibliographie}

[1] Simoons (F. J.) (1970). - Primary adult lactose intolerance and the milking habitat: Problem in biologic and cultural interrelations. II. A culture historical hypotesis. Amer. J. Dig. Dis., 15, 695.

[2] Ferguson (A.) and Maxwell (J. D.) (1967). - Genetic aetiology of lactose intolerance. Lancet, II (7508), 188.

[3] Rosensweig (N.S.) (1971). - Adult lactase deficiency: genetic control or adaptive response ? Gastroenterology, 60 (3), 464.

[4] Lamedica (G. M.), Durand (P.) and Martino (A. M.) (1962). - Intestinal tolerance to disaccharides: the effect of the administration of different doses of lactose to babies in the first three years of life. Consideration of the relationship between lactose metabolism and infantile diarrhoea. Minerva Dietol., 2 (4), 177.

[5] Suncto (S. M.) and Sutedjo (J.) (1971). - Lactose intolerance in chronic diarrhoea among indonesian children. Paediatrica Indonesiana, 11 (5), 1.

[6] Mc Michael (H. B.), Webb (J.) and Dawson (A. M.) (1965). - Lactase deficiency in adults a cause of functional diarrhoea. Lancet, I (7388), 717. 
[7] Dayless (T.M.) and Rosensweig (N.S.) (1966). - A racial difference in incidence of lactose deficiency. Jama, 197, 968.

[8] Huang (S. S.) and Baykess (T. M.) (1968), - Milk and lactose intolerance in healthy orientals. Science, $160,83$.

[9] Paes (I. C.), Searl (P.), Rubert (M. W.) and Faloon (W. W.) (1967). - Intestinal lactase deficiency and saccharide malabsorption during oral neomycin administration. Gastroenterology, 53 (1), 49.

[10] Cain (G. D.) Reiner (E. B.) and Patterson (M.) (1968). - Effect of neomycin on disaccharidase activity of the small bowel. Archs. Intern. Med, 122, (4), 311.

[11] Cerutti (G.) (1968). - Destinazione di attuale interesse del latte e dei duoi derivati: prodotti dietetici, prodotti aromatizzati, prodotti da siero. It latte, 42, 264.

[12] PeRI (C.) (1974). - Applicazioni della osmosi inversa e dell'ultrafiltrazione nelle industrie alimentari. Il latte, 48, 462.

[13] Michaels (A. S.) (1968). - Ultrafiltration. In " Progress in separation and purification ». E. S. Perry, Interscience, New York.

[14] Emaldi (G. C.), Pompei (C.), Carbone (E.) and Peri (C.) (1974). - Composizione e conservabilità di yoghurt preparati con latte concentrato per ultrafiltrazione. Scienza, tecn. latt. casearia, 25 (2), 33.

[15] Resmini (P.), SARAcchi (S.) and PeRI (C) (1974). - Frazionamento e concentrazione dei costituenti azotati nel corso delle ultrafiltrazioni del latte. Il latte, 48, 466.

[16] Pompei (C.) (1974). - Recupero e purificazione delle proteine da latte magro : ottimizzazione del processo. Il latte, 48, 476.

[17] Jolly (R. C.) and Kosikowsкi (F. V.) (1974). - A new blue cheese food material from ultrafiltration process and enzymatic fermentation. J. Dairy Sci., 57, 596.

[18] Maulors (J. L.) et Mocouot (G.) (1971). - Préparation de fromage à partir de " pré-fromage liquide " obtenu par ultrafiltration du lait. Le Lait, $51,495$.

[19] Balducci (A.) (1974). - Concentrazione del siero di pecora per ultrafiltrazione ed utilizzazione dei concentrati per la produzione della ricotta. Il latte, 48, 471.

[20] Morisi (F.), Pastore (M.) and Viglia (A.) (1973). - Reduction of lactose content of milk by entrapped - galactosidase. I. Characteristics of - galactosidase from yeast and Escherichia coli. J. Dairy Sci., 56, 1123.

[21] Wendorff (W. L.), Amundson (C. H.) and Olson (N. F.) (1965). - Production of lactase by yeast fermentation of whey. J. Dairy Sci., 48, 769 .

[22] DLuZEwSKI (M.) (1969). - Studies on lactase and its use in the food industry. I. Production and properties of lactase. Roczn. Technol. Chem. Zywm., $16,21$.

[23] Dluzewski (M.) (1969). - Studies on lactase and its use in food industry. II. Microbiological determination of lactase activity. Roczn. Technol. Chem. Zywm., 16, 33.

[24] Dluzewski (M.) and Loskot (E.) (1969). - Studies on lactase and its use in the food industry. III. Use of lactase in production of whey concentrates. Roczn. Technol. Chem. Zywm., 16, 39.

[25] Thompson (M. P.) and GyuricseK (D. M.) (1974). - Manufacture of yogurt buttermilk and cottage cheese from hydrolyzed lactose milk. J. Dairy Sci., 57,585 . 
[26] Melrose (G. J. H.) (1971). - Insolubilized enzymes. Biochemical applications of synthetic polymers. Rev. P. Appli Chem., 21, 83.

[27] Silman (I. H.) and Katchalski (E.) (1966). - Starter-insoluble derivates of enzymes, antigens and antibodies. Ann. Rev. Biochem., 35, 873.

[28] Hustad (G. O.), Richardson (T.) and Olson (N. F.) (1973). - Immobilization of - galactosidase on a insoluble carrier with a polyisocyanate polymer. I. Preparation and properties. J. Dairy Sci., 56, 1111.

[30] Curt Richter (P.) and James DuKe (R.) (19 ). - Cataracts produced in rats by yogurt. Science, 168, 1372.

[31] Stimpson (E. G.) (1954). - Conversion of lactose to glucose ard galactose. U.S. Pat., 2, 681-858.

[32] Fiehring (G.), Косн (Y.) and Косн (H.) (1972), - A process for the cleavage of lactose. Br. Pat., 262, 203.

[33] Raibaud (P.), Coulet (M.), Galpin (I. V.) et Mocouot (G.) (1961). - J. Appl. Bact., 24, 285.

[34] A.O.A.C. (1970). - Official methods of analysis. Washington (U.S.A.).

[35] Puhan (Z.) and Flueler (O.) (1972). - Thermal destruction of lactic acid bacteria and contaminants in skim-milk and milk fat containing media. Leben. mittelwissenschaft und Technol., 5 (4), 144. 